\title{
Antimicrobial Susceptibility of Lactobacillus delbrueckii subsp. lactis from Milk Products and Other Habitats
}

\author{
Noam Shani ${ }^{1, *(\mathbb{D})}$, Simone Oberhaensli ${ }^{2}$, Hélène Berthoud ${ }^{1} \mathbb{D}$, Remo S. Schmidt ${ }^{3}$ and Hans-Peter Bachmann ${ }^{3}(\mathbb{D})$ \\ 1 Competence Division Methods Development and Analytics, Agroscope, Schwarzenburgstrasse 161, \\ 3003 Bern, Switzerland; helene.berthoud@agroscope.admin.ch \\ 2 Interfaculty Bioinformatics Unit and SIB Swiss Institute of Bioinformatics, University of Bern, Baltzerstrasse 6, \\ 3012 Bern, Switzerland; simone.oberhaensli@bioinformatics.unibe.ch \\ 3 Research Division Food Microbial Systems, Agroscope, Schwarzenburgstrasse 161, 3003 Bern, Switzerland; \\ remo.schmidt@agroscope.admin.ch (R.S.S.); hans-peter.bachmann@agroscope.admin.ch (H.-P.B.) \\ * Correspondence: noam.shani@agroscope.admin.ch
}

Citation: Shani, N.; Oberhaensli, S.; Berthoud, H.; Schmidt, R.S.; Bachmann, H.-P. Antimicrobial Susceptibility of Lactobacillus delbrueckii subsp. lactis from Milk Products and Other Habitats. Foods 2021, 10, 3145. https://doi.org/ $10.3390 /$ foods 10123145

Academic Editor: Giorgio Giraffa

Received: 15 November 2021

Accepted: 15 December 2021

Published: 18 December 2021

Publisher's Note: MDPI stays neutral with regard to jurisdictional claims in published maps and institutional affiliations.

Copyright: (c) 2021 by the authors. Licensee MDPI, Basel, Switzerland This article is an open access article distributed under the terms and conditions of the Creative Commons Attribution (CC BY) license (https:// creativecommons.org/licenses/by/ $4.0 /)$

\begin{abstract}
As components of many cheese starter cultures, strains of Lactobacillus delbrueckii subsp lactis $(L D L)$ must be tested for their antimicrobial susceptibility to avoid the potential horizontal transfer of antibiotic resistance (ABR) determinants in the human body or in the environment. To this end, a phenotypic test, as well as a screening for antibiotic resistance genes (ARGs) in genome sequences, is commonly performed. Historically, microbiological cutoffs (MCs), which are used to classify strains as either 'sensitive' or 'resistant' based on the minimal inhibitory concentrations (MICs) of a range of clinically-relevant antibiotics, have been defined for the whole group of the obligate homofermentative lactobacilli, which includes $L D L$ among many other species. This often leads to inaccuracies in the appreciation of the ABR status of tested $L D L$ strains and to false positive results. To define more accurate MCs for $L D L$, we analyzed the MIC profiles of strains originating from various habitats by using the broth microdilution method. These strains' genomes were sequenced and used to complement our analysis involving a search for ARGs, as well as to assess the phylogenetic proximity between strains. Of $L D L$ strains, $52.1 \%$ displayed MICs that were higher than the defined MCs for kanamycin, 9.9\% for chloramphenicol, and 5.6\% for tetracycline, but no ARG was conclusively detected. On the other hand, all strains displayed MICs below the defined MCs for ampicillin, gentamycin, erythromycin, and clindamycin. Considering our results, we propose the adaptation of the MCs for six of the tested clinically-relevant antibiotics to improve the accuracy of phenotypic antibiotic testing.
\end{abstract}

Keywords: antimicrobial susceptibility; Lactobacillus delbrueckii; broth microdilution; kanamycin; genome sequencing; SNP-based phylogeny

\section{Introduction}

The thermophilic lactic acid bacterium (LAB) Lactobacillus delbrueckii is important in many traditional fermented foods prepared worldwide (Table 1), and three subspecies (bulgaricus, delbrueckii, and lactis) have a long history of safe use [1]. To date, six subspecies have been described: L. delbrueckii subsp. bulgaricus $(L D B)$, L. delbrueckii subsp. delbrueckii $(L D D)$, L. delbrueckii subsp. indicus (LDI), L. delbrueckii subsp. jakobsenii (LDJ), L. delbrueckii subsp. lactis $(L D L)$, and L. delbrueckii subsp. sunkii (LDS). In dairy fermentations, $L D B$ is mainly used in yogurt making, whereas $L D L$ is traditionally used in the production of cooked cheeses, owing its tolerance to the high temperatures during the early phases of cheese manufacturing. Both subspecies seem to have developed a similar adaptation towards optimized utilization of milk resources through reductive evolution and limited acquisition of particular functions. In its evolutionary path, $L D B$ lost more functions than $L D L$ and has thus further diverged from their common ancestor [2]. 
In yogurt fermentation, the so-called protocooperation between Streptococcus salivarius subsp. thermophilus and $\angle D B$, both of which grow in a mutualistic interaction by taking advantage of each other's metabolism, has long been described [3]. Recent findings have indicated that in cheese, a similar mutualistic interaction may take place between $S$. salivarius subsp. thermophilus and LDL [4]. The production of semi-hard (e.g., Appenzeller ${ }^{\circledR}$ and Tête de Moine PDO), hard (e.g., Emmentaler PDO, Le Gruyère PDO, and Comté PDO), and extra-hard cooked cheeses (e.g., Parmigiano Reggiano PDO, Grana Padano PDO, and Sbrinz PDO) relies on the acidification of milk by thermophilic starter cultures containing a combination of thermophilic LAB. A recent metagenomics study has revealed the presence of S. salivarius subsp. thermophilus, Lactobacillus helveticus and LDL in natural whey cultures used to produce Le Gruyère PDO [5]. Defined starter cultures are relatively commonly exclusively composed of $S$. salivarius subsp. thermophilus and $L D L$. The latter is responsible for the second phase of lactic acid fermentation given its lower $\mathrm{pH}$ optimum and its ability to ferment galactose besides glucose. $L D L$ is thus of primary importance in the production of most types of cooked cheese [6]. Given its considerable peptidase complement and its cell envelope-associated proteinase activity, it contributes significantly to proteolysis. These characteristics, together with its propensity to undergo autolysis, confers $L D L$ the ability to influence the development of flavor and texture during cheese ripening [7-9].

Similar to most LAB that constitute starter cultures, new strains of $L D L$ and $L D B$ used in food or feed applications are exempt of a full safety assessment, due to their qualified presumption of safety (QPS) status [10]. Nonetheless, several safety aspects must still be monitored, one of them being the absence of acquired resistance to clinically relevant antimicrobials [11]. The spread of antibiotic resistance genes (ARGs) has become a major issue in the last decades, threatening the efficacy of antibiotics used for medical purposes. Thus, limiting the dissemination of ARGs is an important measure, besides others, to prevent the development of antibiotic resistant bacteria [12]. It is in this respect that the bacteria introduced into the food chain through fermented foods become a concern. Indeed, fermented foods serve as a vehicle for bacteria to enter the body, where the exchange of genes, including ARGs, has been reported to occur [13-15]. To prevent the spread of ARGs through fermented foods, the European Food Safety Authority (EFSA) requires that strains deliberately introduced into the food chain should be devoid of acquired transferable antibiotic resistance (ABR) determinants [16]. Consequently, producers of bacterial cultures have to determine the ABR status of the strains they bring onto the market, even those belonging to species with a QPS status and meant for food production [10].

The EFSA Panel on Additives and Products or Substances used in Animal Feed (FEEDAP) recommends testing bacteria intended to be introduced into the food chain for nine antibiotics selected for their human and veterinary importance. To this end, minimal inhibitory concentrations (MICs) of these antibiotics should be determined using a standardized and internationally recognized phenotypic test [17]. For each antibiotic, a microbiological cutoff (MC) has been defined for several LAB taxa based on the available data. MCs are used as a basis to distinguish the strains with acquired antibiotic resistance from the susceptible ones. Although the absence of ARGs is already a good indication of a strain's safety in terms of ABR, phenotypic tests allow for the detection of unknown ABR mechanisms or of common mechanisms that could not be detected with genomic assessment due, e.g., to potential methodological issues.

Because no MCs have been defined specifically for L. delbrueckii or its subspecies, MICs obtained for strains of LDL have to be compared with the MCs defined for obligate homofermentative lactobacilli, which include dozens of different phylogenetically related species [18]. The necessity of grouping all these species to define their MCs probably stems from the scarcity of ABR data for L. delbrueckii and other obligate homofermentative species; however, this approach could eventually lead to inaccuracies. For culture producers, this may have serious consequences, such as putting aside their assortment strains with interesting technological properties or introducing into the market strains with undetected ABR [19]. 
This study aimed to challenge the current MCs for L. delbrueckii, more specifically for $L D L$. To this end, we assessed antibiotic susceptibility at the genomic and phenotypic levels for 100 strains of L. delbrueckii isolated from various habitats. Based on the measured MICs and our calculations, we propose the revision of the recommended MCs for LDL for several antimicrobials.

Table 1. Subspecies of Lactobacillus delbrueckii isolated from various fermented food products (reviewed by [7,20,21]).

\begin{tabular}{|c|c|c|c|}
\hline Product & Substrate & $\begin{array}{c}\text { Subspecies of Lactobacillus } \\
\text { delbrueckii }\end{array}$ & Country \\
\hline Cheese & Animal milk & $\begin{array}{l}\text { L. delbrueckii subsp. delbrueckii, } \\
\text { L. delbrueckii subsp. lactis }\end{array}$ & Worldwide \\
\hline Dahi & $\begin{array}{l}\text { Cow } / \text { buffalo milk, starter } \\
\text { culture }\end{array}$ & L. delbrueckii subsp. indicus & $\begin{array}{l}\text { India, Nepal, Sri Lanka, } \\
\text { Bangladesh, Pakistan }\end{array}$ \\
\hline $\begin{array}{l}\text { Misti dahi (mishti doi, lal dahi, } \\
\text { payodhi) }\end{array}$ & Cow/buffalo milk & L. delbrueckii subsp. bulgaricus & India, Bangladesh \\
\hline $\begin{array}{c}\text { Tarag, Khoormog, Airag, } \\
\text { Kumys }\end{array}$ & Cow/yak/goat/mare milk & L. delbrueckii subsp. bulgaricus & Mongolia \\
\hline Yogurt & Animal milk & L. delbrueckii subsp. bulgaricus & Europe, Australia, America \\
\hline Idli & $\begin{array}{l}\text { Rice, black gram, or other } \\
\text { dehusked pulses }\end{array}$ & L. delbrueckii & $\begin{array}{c}\text { India, Sri Lanka, Malaysia, } \\
\text { Singapore }\end{array}$ \\
\hline Poto poto & Maize & L. delbrueckii & Congo \\
\hline Sourdough & Rye, wheat & L. delbrueckii & Europe, Australia, America \\
\hline Kimchi & $\begin{array}{l}\text { Cabbage, green onion, hot } \\
\text { pepper, ginger }\end{array}$ & L. delbrueckii & Korea \\
\hline Kha Nhom Jeen & Rice & L. delbrueckii & Thailand \\
\hline Soibum & Bamboo shoot & L. delbrueckii & India \\
\hline Sunki & Turnip & L. delbrueckii & Japan \\
\hline Tarhana & $\begin{array}{l}\text { Wheat flour, yogurt, } \\
\text { vegetables, spices }\end{array}$ & L. delbrueckii & Turkey \\
\hline Tauco & Soybean & L. delbrueckii & Indonesia \\
\hline Tsukemono & Pickled vegetable & L. delbrueckii & Japan \\
\hline
\end{tabular}

\section{Materials and Methods}

\subsection{Bacterial Strains and Culture Conditions}

A total of 101 strains of L. delbrueckii were selected for analysis (Table 2). Identification using matrix-assisted laser desorption-ionization time of flight (MALDI-TOF) and genome comparison based on the calculated average nucleotide identity (ANI) values (see Identification using MALDI-TOF and Average Nucleotide Identities) revealed inaccuracies in the taxonomic assignments. One strain assigned to another species was excluded from this study. After being re-assigned at the subspecies level, the remaining $100 \mathrm{~L}$. delbrueckii strains ( $80 L D L, 17 L D B$, and three $L D S$ ) were further analyzed. Seventy-eight strains obtained from various dairy products or dairy starter cultures, two from distilleries, one from human urine, one from human saliva, one from dried calf stomachs, one from fermented vegetables (sunki), and 16 others were of unknown origin. Six strains were constituents of commercial starter cultures used in the cheese industry. 
Table 2. Bacterial strains and their taxonomic affiliation, origin, and year of isolation.

\begin{tabular}{|c|c|c|c|c|c|c|c|}
\hline No. & Subspecies ${ }^{b}$ & Strain ID & Culture Collection ${ }^{a}$ & Origin & Year of Isolation & $\begin{array}{l}\text { Original Depositor; } \\
\text { Strain Designation }\end{array}$ & $\begin{array}{l}\text { GenBank Assembly } \\
\text { Accessions }{ }^{d}\end{array}$ \\
\hline 1 & $L D L$ & FAM 1200 & ACC & Unknown & Unknown & FAM 1200 & GCA_021135575.1 \\
\hline 2 & $L D L$ & FAM 8520 & $\mathrm{ACC}$ & Swiss milk & Unknown & Jimeno, J.; FM 1 & GCA_021135595.1 \\
\hline 3 & $L D L$ & FAM 10980 & $\mathrm{ACC}$ & Swiss undefined mixed starter culture & 1979 & Isolini, D.; Lb 101.07 & GCA_021135555.1 \\
\hline 4 & $L D L$ & FAM 10983 & ACC & Swiss undefined mixed starter culture & 1984 & Isolini, D.; Lb 101.10 & GCA_021135485.1 \\
\hline 5 & $L D L$ & FAM 10991 & ACC & Swiss undefined mixed starter culture & 1980 & Isolini, D.; Lb 104.80 & GCA_021135515.1 \\
\hline 6 & $L D L$ & FAM 11021 & ACC & Swiss undefined mixed starter culture & 1982 & Isolini, D.; Lb 115.53 & GCA_021135535.1 \\
\hline 7 & $L D L$ & FAM 11036 & ACC & Swiss undefined mixed starter culture & 1979 & Isolini, D.; Lb 119.17 & GCA_021135475.1 \\
\hline 9 & $L D L$ & FAM 11108 & ACC & Swiss undefined mixed starter culture & 1983 & Isolini, D.; Lb 157.02 & GCA_021135435.1 \\
\hline 10 & $L D L$ & FAM 11129 & $\mathrm{ACC}$ & Swiss undefined mixed starter culture & 1983 & Isolini, D.; Lb 164.35 & GCA_021135405.1 \\
\hline 11 & $L D L$ & FAM 11142 & $\mathrm{ACC}$ & Swiss undefined mixed starter culture & 1988 & Isolini, D.; Lb 202.02 & GCA_021135395.1 \\
\hline 12 & $L D L$ & FAM 12062 & $\mathrm{ACC}$ & Swiss undefined mixed starter culture & 1983 & Isolini, D.; Lb 302.01 & GCA_021135375.1 \\
\hline 13 & $L D L$ & FAM 12103 & $\mathrm{ACC}$ & Swiss undefined mixed starter culture & 1986 & Isolini, D.; Lb 325.13 & GCA_021135355.1 \\
\hline 14 & $L D L$ & FAM 12107 & ACC & Swiss undefined mixed starter culture & 1988 & Isolini, D.; Lb 202.07 & GCA_021135335.1 \\
\hline 15 & $L D L$ & FAM 12109 & ACC & Swiss undefined mixed starter culture & 1988 & Isolini, D.; Lb 202.09 & GCA_021135275.1 \\
\hline 16 & $L D L$ & FAM 18834 & ACC & Swiss milk & 2005 & Unknown; $\mathrm{C} 1$ & GCA_021135295.1 \\
\hline 17 & $L D L$ & FAM 19699 & ACC & Swiss Emmental cheese & 1989-1990 & Isolini, D.; 23.10 & GCA_021135315.1 \\
\hline 19 & $L D L$ & FAM 20408 & $\mathrm{ACC}$ & Swiss hard cheese & 1989-1990 & Isolini, D.; LDELA 871-33 & GCA_021135235.1 \\
\hline 20 & $L D L$ & FAM 20544 & $\mathrm{ACC}$ & Swiss hard cheese & 1989-1990 & Isolini, D.; LDEBU 927-84 & GCA_021135205.1 \\
\hline 21 & $L D L$ & FAM 21277 & ACC & Swiss undefined mixed starter culture & Unknown & Meyer, J.; 101/100 & GCA_005864055.1 \\
\hline 22 & $L D L$ & FAM 21376 & ACC & Swiss undefined mixed starter culture & Unknown & Meyer, J.; 169/126 & GCA_021135175.1 \\
\hline 23 & $L D L$ & FAM 21745 & ACC & Swiss undefined mixed starter culture & 1979 & Isolini, D.; Lb 101.01 & GCA_021135195.1 \\
\hline 24 & $L D L$ & FAM 21748 & ACC & Swiss undefined mixed starter culture & 1979 & Isolini, D.; Lb 101.56 & GCA_021135155.1 \\
\hline 25 & $L D L$ & FAM 21753 & ACC & Swiss undefined mixed starter culture & 1981 & Isolini, D.; Lb 124.49 & GCA_021135095.1 \\
\hline 26 & $L D L$ & FAM 21754 & $\mathrm{ACC}$ & Swiss undefined mixed starter culture & 1982 & Isolini, D.; Lb 153.48 & GCA_021135135.1 \\
\hline 27 & $L D L$ & FAM 21755 & $\mathrm{ACC}$ & Swiss undefined mixed starter culture & 1982 & Isolini, D.; Lb 153.08 & GCA_021135105.1 \\
\hline 28 & $L D L$ & FAM 21756 & $\mathrm{ACC}$ & Swiss undefined mixed starter culture & 1982 & Isolini, D.; Lb 153.09 & GCA_021135075.1 \\
\hline 29 & $L D L$ & FAM 21768 & $\mathrm{ACC}$ & Swiss undefined mixed starter culture & 1982 & Isolini, D.; Lb 153.20 & GCA_021135055.1 \\
\hline 30 & $L D L$ & FAM 21769 & $\mathrm{ACC}$ & Swiss undefined mixed starter culture & 1978 & Isolini, D.; Lb 150.10 & GCA_021135025.1 \\
\hline 31 & $L D L$ & FAM 21781 & $\mathrm{ACC}$ & Swiss undefined mixed starter culture & 1981 & Isolini, D.; Lb 124.09 & GCA_021135015.1 \\
\hline 32 & $L D L$ & FAM 21783 & $\mathrm{ACC}$ & Swiss undefined mixed starter culture & 1982 & Isolini, D.; Lb 153.27 & GCA_021134955.1 \\
\hline 33 & $L D L$ & FAM 21784 & ACC & Swiss undefined mixed starter culture & 1982 & Isolini, D.; Lb 153.28 & GCA_005864125.1 \\
\hline
\end{tabular}


Table 2. Cont.

\begin{tabular}{|c|c|c|c|c|c|c|c|}
\hline No. & Subspecies ${ }^{b}$ & Strain ID & Culture Collection $^{\text {a }}$ & Origin & Year of Isolation & $\begin{array}{l}\text { Original Depositor; Strain } \\
\text { Designation }\end{array}$ & $\begin{array}{l}\text { GenBank Assembly } \\
\text { Accessions }{ }^{d}\end{array}$ \\
\hline 34 & $L D L$ & FAM 22091 & $\mathrm{ACC}$ & Swiss natural whey culture & 1973 & A50.2 & GCA_021134995.1 \\
\hline 35 & $L D L$ & FAM 22092 & ACC & Swiss natural whey culture & 1977 & A56.1 & GCA_021134975.1 \\
\hline 37 & $L D L$ & FAM 22274 & $\mathrm{ACC}$ & Swiss natural whey culture & 1968 & A 44.2 & GCA_021134915.1 \\
\hline 38 & $L D L$ & FAM 22332 & $\mathrm{ACC}$ & Swiss undefined mixed starter culture & Unknown & Weishaupt, C.; 313.1 & GCA_021134885.1 \\
\hline 39 & $L D L$ & FAM 22680 & ACC & Swiss natural whey culture & 1967 & A77.5 & GCA_021134855.1 \\
\hline 40 & $L D L$ & FAM 24199 & $\mathrm{ACC}$ & Swiss Tomme cheese & 2017 & Shani, N.; 55/8 & GCA_021134875.1 \\
\hline 42 & $L D L$ & CIP 110109 & CIP & $\begin{array}{l}\text { Human urine, France } \\
\text { Artisanal lactic starter (for Gruyère de }\end{array}$ & 1976 & Vandekerkove; 103-76 & GCA_021134765.1 \\
\hline 43 & $L D L^{\mathrm{c}}$ & CIRM BIA 225 & CIRM & $\begin{array}{l}\text { Comté cheese making), } \\
\text { Franche-Comté, France }\end{array}$ & 1963 & Accolas, J.P.; P12 & GCA_021134795.1 \\
\hline 44 & $L D L$ & CIRM BIA 229 & CIRM & $\begin{array}{l}\text { Artisanal lactic starter (for Gruyère de } \\
\text { Comté cheese making), } \\
\text { Franche-Comté, France }\end{array}$ & 1964 & Accolas, J.P.; H5a & GCA_021134815.1 \\
\hline 45 & $L D L$ & CIRM BIA 230 & CIRM & Cheese (Emmental), Finland & 1968 & CNRZ331 & GCA_021134745.1 \\
\hline 46 & $L D L$ & CIRM BIA 233 & CIRM & Probably a French yoghurt factory & 1984 & Cluzel, P.J.; LT4-G2N & GCA_021134735.1 \\
\hline 48 & $L D L$ & CIRM BIA 265 & CIRM & Cheese (Emmental), Finland & 1968 & CNRZ330 & GCA_021134675.1 \\
\hline 49 & $L D S(L D L)$ & CIRM BIA 266 & CIRM & Fermented milk (kefir), Russia & 1971 & Accolas, J.P.; KFA1 & GCA_021134645.1 \\
\hline 50 & $L D L$ & CIRM BIA 267 & CIRM & $\begin{array}{c}\text { Lactic starter (for Emmental cheese } \\
\text { making), Finland }\end{array}$ & 1974 & Tybeck, E., LKT; VALIO & GCA_021134615.1 \\
\hline 51 & $L D L$ & CIRM BIA 269 & CIRM & $\begin{array}{l}\text { Artisanal lactic starter (for Emmental } \\
\text { cheese making), Finland }\end{array}$ & Unknown & Tybeck, E.; ISL 19 & GCA_021134635.1 \\
\hline 52 & $L D L$ & CIRM BIA 1368 & CIRM & $\begin{array}{l}\text { Starter (for Grana Padano cheese } \\
\text { making), Piedmont, Italy }\end{array}$ & 1988 & IMPC Al & GCA_021134595.1 \\
\hline 53 & $L D L$ & CIRM BIA 1372 & CIRM & Yak milk, Nepal & 1996 & Quenee, P.; Np 5t & GCA_021134505.1 \\
\hline 54 & $L D L$ & CIRM BIA 1374 & CIRM & $\begin{array}{l}\text { Whey (from Comté), Franche-Comté, } \\
\text { France }\end{array}$ & 1993 & CML10 & GCA_021134545.1 \\
\hline 55 & $L D L^{\mathrm{c}}$ & DSM $20072^{\mathrm{T}}$ & DSMZ & $\begin{array}{c}\text { Emmental cheese (country of origin } \\
\text { unknown) }\end{array}$ & Before 22.08.1990 & $\begin{array}{l}\text { Snog-Kjaer, A. (Orla-Jensen, S., } \\
\text { Thermobacterium lactis No. 10) }\end{array}$ & GCA_002278095.1 \\
\hline 56 & $L D L$ & DSM 20073 & DSMZ & Saliva (country of origin unknown) & Before 22.08.1990 & Williams, N.; 14-1 & GCA_021134535.1 \\
\hline 57 & $L D L$ & DSM 20076 & DSMZ & Unknown & Before 22.08.1990 & Fred, E.B.; F 59 & GCA_021134495.1 \\
\hline
\end{tabular}


Table 2. Cont

\begin{tabular}{|c|c|c|c|c|c|c|c|}
\hline No. & Subspecies $^{\mathbf{b}}$ & Strain ID & Culture Collection $^{\text {a }}$ & Origin & Year of Isolation & $\begin{array}{l}\text { Original Depositor; Strain } \\
\text { Designation }\end{array}$ & $\begin{array}{l}\text { GenBank Assembly } \\
\text { Accessions }{ }^{d}\end{array}$ \\
\hline 58 & $L D L$ & DSM 20355 & DSMZ & Unknown & Before 22.08.1990 & McCoy; Ld 5 & GCA_021134475.1 \\
\hline 59 & $L D L$ & NCIMB 7278 & NCIMB & Unknown & Before 01.01.1950 & Dorner, W.; $39 \mathrm{E} / \mathrm{K}$ & GCA_021134455.1 \\
\hline 61 & $L D L$ & NCIMB 8140 & NCIMB & "Ga" starter culture & Before 01.09.1956 & "u" Ga" & GCA_021134435.1 \\
\hline 62 & $L D L$ & NCIMB 8170 & NCIMB & Unknown & Before 1999 & Merck \& Co., Inc.; MB 367 & GCA_021134415.1 \\
\hline 63 & $L D L$ & NCIMB 8183 & NCIMB & Unknown & Before 30.11 .1950 & McCoy, E.; 326 & GCA_021134395.1 \\
\hline 64 & $L D L$ & NCIMB 8882 & NCIMB & Unknown & Before 01.07.1957 & Winkler, K.C.; 1175 & GCA_021134335.1 \\
\hline 66 & $L D L$ & NCIMB 700280 & NCIMB & Unknown & Before 01.01.1954 & 244 & GCA_021134355.1 \\
\hline 67 & $L D L^{\mathrm{c}}$ & NCIMB 700820 & NCIMB & Unknown & Before 01.01.1954 & $\mathrm{C} 808 / 5$ & GCA_021134295.1 \\
\hline 68 & $L D L$ & NCIMB 700860 & NCIMB & Unknown & Before 01.01.1956 & $18 / 40$ & GCA_021134275.1 \\
\hline 69 & $L D L$ & NCIMB 701040 & NCIMB & Italian hard cheese & Before 01.01.1957 & $\mathrm{C} 14 / 8$ & GCA_021134235.1 \\
\hline 70 & $L D L$ & NCIMB 701437 & NCIMB & Unknown & Unknown & Snog-Kjaer, A.; LI 1 & GCA_021134215.1 \\
\hline 71 & $L D L$ & NCIMB 702465 & NCIMB & $\begin{array}{c}\text { Dried calve stomachs for Gruyere } \\
\text { cheese }\end{array}$ & Unknown & $\mathrm{L} 24, \mathrm{C} 57$ & GCA_021134255.1 \\
\hline 72 & $L D L$ & NCIMB 702466 & NCIMB & Switzerland & Unknown & Ritter, P.; L26, H14, 1304 & GCA_021134175.1 \\
\hline 73 & $L D L$ & NCIMB 702467 & NCIMB & Sweden & Before 01.01.1981 & Swartling, P.; L27, L39 (WL39) & GCA_021134185.1 \\
\hline 75 & $L D L(L D D)$ & NCIMB 702469 & NCIMB & Distillery & Before 01.01.1961 & Sharpe, M.E.; LE8, M2/3 & GCA_021134135.1 \\
\hline 76 & $L D L$ & FAM 24847 & NC & Commercial cheese starter culture & 2019 & na & GCA_021134095.1 \\
\hline 77 & $L D L$ & FAM 24848 & $\mathrm{NC}$ & Commercial cheese starter culture & 2019 & na & GCA_021134115.1 \\
\hline 78 & $L D L$ & FAM 24849 & $\mathrm{NC}$ & Commercial cheese starter culture & 2019 & na & GCA_021134075.1 \\
\hline 79 & $L D L$ & FAM 24850 & $\mathrm{NC}$ & Commercial cheese starter culture & 2019 & na & GCA_021134035.1 \\
\hline 80 & $L D L$ & FAM 24851 & NC & Commercial cheese starter culture & 2019 & na & GCA_021134055.1 \\
\hline 81 & $L D L$ & FAM 24852 & NC & Commercial cheese starter culture & 2019 & na & GCA_021134005.1 \\
\hline 82 & $L D B$ & FAM 22166 & $\mathrm{ACC}$ & Swiss natural whey culture & 1968 & A135.3 & GCA_021133995.1 \\
\hline 83 & $L D B$ & FAM 22754 & ACC & Yoghurt & 1952 & A171.1 & GCA_021133975.1 \\
\hline 84 & $L D B$ & CIRM BIA 657 & CIRM & Fermented milk, Crete, Greece & 1987 & Zourari, A.; ZL071B1 & GCA_021133935.1 \\
\hline 85 & $L D B$ & CIRM BIA 773 & CIRM & $\begin{array}{l}\text { Lactic starter (for yoghurt making), } \\
\text { Île-de-France, France }\end{array}$ & 1963 & Chevalier, R.; LT1 & GCA_021133955.1 \\
\hline 86 & $L D B$ & CIRM BIA 860 & CIRM & $\begin{array}{l}\text { Lactic starter (for yoghurt making), } \\
\text { Rhône-Alpes, France }\end{array}$ & 1971 & Accolas, J.P.; LAY 1 & GCA_021133915.1 \\
\hline 87 & $L D B$ & CIRM BIA 864 & CIRM & Fermented milk, France & Unknown & IL1609 & GCA_021133885.1 \\
\hline
\end{tabular}


Table 2. Cont.

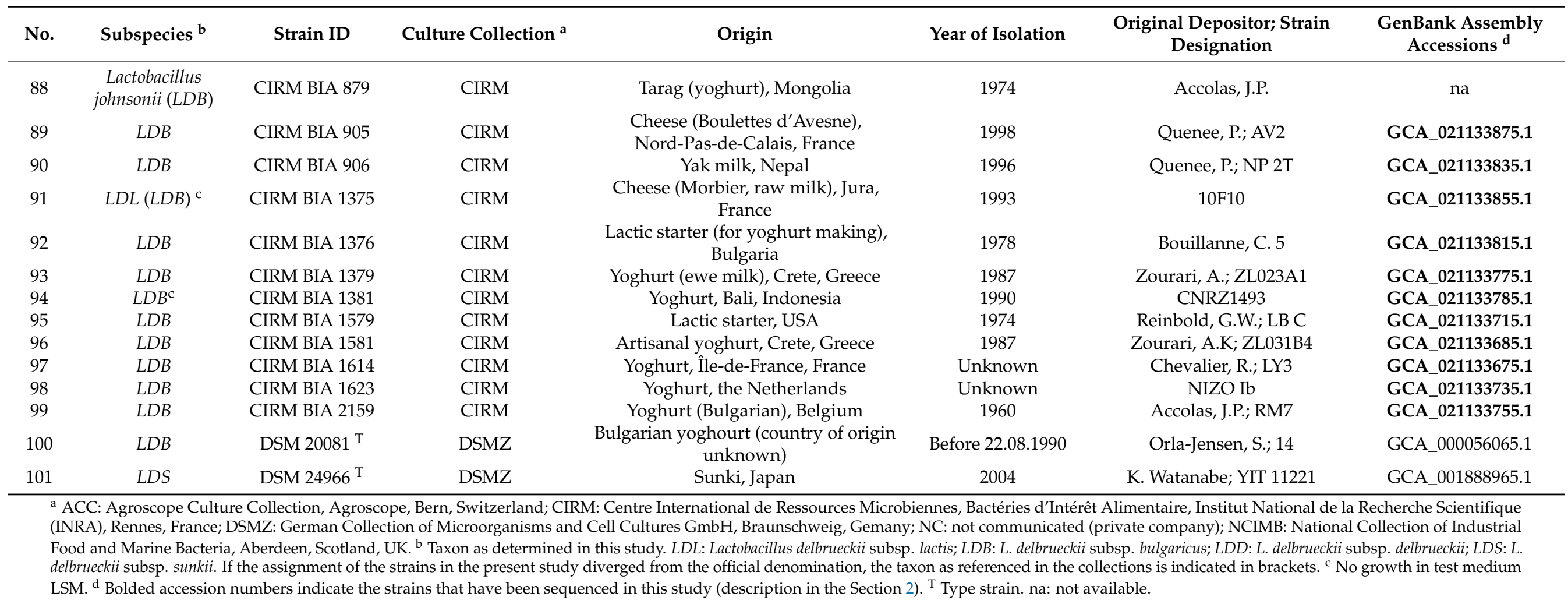


The strains were stored at $-80{ }^{\circ} \mathrm{C}$ in De Man, Rogosa, Sharpe (MRS) [22] broth with Tween 80 (Biolife Italiana Srl, Milan, Italy) containing sterile low-fat milk as the cryoprotectant. They were routinely cultured in MRS broth with Tween 80 at $37{ }^{\circ} \mathrm{C}$ under aerobic conditions. The absence of contaminants was confirmed by plating 10 -fold serial dilutions in $10 \mathrm{~mL} 0.9 \% \mathrm{NaCl}$ onto MRS agar plates and by observing the colony morphologies and the cells under a microscope.

\subsection{Species-Level Identification}

The identities of the strains were verified using MALDI-TOF on a MicroFlex ${ }^{\mathrm{TM}} \mathrm{LT} / \mathrm{SH}$ MS (Bruker Daltonics, Bremen, Germany), as described previously [23]. Data were acquired with FlexControl v. 3.4.105. Spectra were analyzed by the MBT Compass software v.1.4 (Bruker Daltonics, Inc., Billerica, MA, USA) and by Realtime Classification Biotyper MBT RUO 3.1 with BDAL v11.0 library.

\subsection{Genome Sequences of the L. delbrueckii Strains}

Available assemblies were downloaded from the National Center for Biotechnology Information (NCBI). Strains with unavailable assemblies in open databases were sequenced de novo. Their DNA was extracted as described previously [24]. Quality control assessment of the extracted DNA, library generation, and sequencing runs were performed on the Next Generation Sequencing Platform, University of Bern, Switzerland. In brief, the libraries were prepared using a TruSeq DNA PCR-free Library Prep kit (Illumina, 20015963, San Diego, CA, USA) in combination with TruSeq DNA UD Indexes (Illumina, 20022370) according to Illumina's guidelines. Pooled DNA libraries were sequenced by paired-end sequencing $(2 \times 150 \mathrm{bp}$ or $2 \times 250 \mathrm{bp})$ either on an HiSeq 3000 instrument, or using a shared Illumina NovaSeq 6000 S Prime (SP) Reagent Kit (20029137; 500 cycles; Illumina, San Diego, CA, USA) on an Illumina NovaSeq 6000 instrument, generating an average of 4.3 million reads/library. ConFindr v.0.7.2 was used with raw reads to check the intra-species bacterial contamination [25]. Quality control of raw data was performed with FastQC v.0.11.7 [26]. Adaptor removal and trimming of raw data were performed using fastp v.0.20.0 [27]. The trimmed reads were assembled with SPAdes v.3.14.0 [28] in the -isolate mode, and contigs shorter than $200 \mathrm{bp}$ were removed from the final assembly. QUAST v.4.6 [29] and BUSCO v.4.0.6 [30] were used in the -auto-lineage-prok mode to assess the quality of the assemblies. Newly obtained assemblies were uploaded to NCBI. Taxonomic affiliation of the assemblies was performed at the species level using the GTDB-Tk v.0.3.2 'classify' workflow and reference data version r89 to confirm the previous identification. The Whole Genome Shotgun projects of the strains sequenced in this study have been deposited at GenBank under BioProject PRJNA777018 with GenBank WGS accessions JAJNSH000000000-JAJNVX000000000. The version described in this paper is version 01.

\subsection{Average Nucleotide Identities (ANIs)}

The assignment of the strains at the subspecies level was checked by calculating ANI values using fastANI [31]. Assemblies of the type strains of $L D D$ (DSM $20074^{\mathrm{T}}$ GenBank assembly accession GCA_001908495.1), LDS (JCM $17838^{\mathrm{T}}$, GenBank assembly accession GCA_001888965.1), LDI (JCM 15610 T , GenBank assembly accession GCA_001908415.1), and LDJ (DSM $26046^{\mathrm{T}}$, GenBank assembly accession GCA_001888925.1) were included in the analysis. Visualization was done using the package gplots v.3.1.1 [32] using RStudio Pro v.1.4.1103-4 [33] and the R software v.4.0.3 [34].

\subsection{Strains' Phylogeny}

Phylogenetic relationships of the isolates were assessed using PhaME v.1.0.2 [35] and IQ-TREE multicore v.2.0.3 [36], as described previously [19]. $L D L$ and $L D B$ were assessed separately. The resulting trees were visualized with the Interactive Tree Of Life (iTOL) v.5 [37]. Pairs of isolates with fewer than 50 single nucleotide polymorphisms (SNPs) in the 
SNP pairwise matrix from PhaME were considered to be possibly identical. In such cases, their origins and years of isolation were taken as an additional information to determine whether they should be considered different 'strains in the taxonomic sense' [38].

\subsection{Screening Assemblies for ARGs}

The genome assemblies were screened for known transferrable ABR genes with ABRicate [39] using the default filtering parameters (minimum DNA \%identity $=75$ and minimum DNA \%coverage $=0$ ) and with the databases NCBI AMRFinderPlus [40], CARD 2017 [41,42], ARG-ANNOT v.4 [43], and Resfinder v.3.0 [44]. The genome assembly of P. acidilactici FAM 13875 (GenBank assembly accession GCA_009789085.1), which harbors the $\mathrm{ABR}$ genes tet $M$ and ermA [23], was included as positive control.

\subsection{Antibiotic Susceptibility Testing and MC Determination}

The existing MCs were evaluated based on the Standard Operating Procedure (SOP) 10.1 of the EUCAST [45]. The antibiotic susceptibility of the strains was tested at the Culture Collection of Switzerland (CCOS, Wädenswil, Switzerland) using a broth microdilution susceptibility method following the standard procedure of the International Organization for Standardization ISO 10932 I IDF 223:2010 [46], as recommended by the FEEDAP [17]. In brief, the strains were propagated in MRS broth with Tween 80 (Biolife Italiana Srl, Milan, Italy) at $37^{\circ} \mathrm{C}$ for $24 \mathrm{~h}$ and plated on MRS agar with Tween 80 (Biolife Italiana Srl, Milan, Italy). Standardized inocula were obtained by suspending colonies in a sterile saline solution to a turbidity of McFarland 1. The suspensions were then diluted 1000 times and transferred into microplates containing LAB susceptibility medium (LSM) [47] and different antibiotics of varying concentrations: ampicillin (AMP, $0.03-16 \mu \mathrm{g} / \mathrm{mL}$ ), vancomycin (VAN, $0.25-128 \mu \mathrm{g} / \mathrm{mL}$ ), gentamycin (GEN, $0.5-256 \mu \mathrm{g} / \mathrm{mL}$ ), kanamycin (KAN, 2-1024 $\mu \mathrm{g} / \mathrm{mL}$ ), streptomycin (STR, 0.5-256 $\mu \mathrm{g} / \mathrm{mL}$ ), erythromycin (ERY, 0.016-8 $\mu \mathrm{g} / \mathrm{mL}$ ), clindamycin (CLI, 0.03-16 $\mu \mathrm{g} / \mathrm{mL}$ ), tetracycline (TET, 0.12-64 $\mu \mathrm{g} / \mathrm{mL}$ ), and chloramphenicol (CHL, $0.12-64 \mu \mathrm{g} / \mathrm{mL}$ ). The microdilution plates were incubated at $37^{\circ} \mathrm{C}$ for $48 \mathrm{~h}$ under anaerobic conditions. Growth was assessed visually.

The MIC distributions of the antibiotics were processed in the ECOFFinder program v2.1 (available at http://www.eucast.org/fileadmin/src/media/PDFs/EUCAST_files/ MIC_distributions/ECOFFinder_XL_2010_v2.1_web_version.xlsm (accessed on 28 July 2021) [48] and the MCs were defined as the $99.0 \%$ ECOFF values. The MIC distributions and the MCs were visualized with the ggplot2 package v. 3.3.3 [49] using RStudio Pro v. 1.4.1103-4 [33] with the R software v. 4.0.3 [34].

\section{Results}

\subsection{Taxonomic Assignment and ANIs}

At the species level, the identity of most strains was confirmed using MALDI-TOF and GTDB-tk. Only strain CIRM BIA 879 was assigned to L. johnsonii and was excluded from the subsequent analyses.

Based on the ANI values, $L D B$ formed a well-defined cluster, with pairs of strains displaying ANI similarities at $98.83-100 \%$ (median $99.19 \%$ ), and it was evidently distinct from the other L. delbrueckii subspecies (Figure S1). By contrast, the $L D L$ strains formed a quite inhomogeneous cluster (ANI $97.59-100 \%$, median $98.79 \%$ ), although it was still evidently divergent from the other L. delbrueckii subspecies.

The taxonomic assignment at the subspecies level was re-evaluated for three strains (Table 2): CIP 101810 and CIRM BIA 266 (both originally assigned to LDL) displayed a high similarity $\left(98.27 \%\right.$ and $98.61 \%$, respectively) with the LDS type strain DSM $24966^{\mathrm{T}}$, and CIRM BIA 1375 (originally LDB) displayed similarity with LDL DSM 20072 ${ }^{\mathrm{T}}(98.53 \%$ ). NCIMB 702468 and NCIMB 702469, referenced in the NCIMB database as LDS and LDD, respectively, were assigned to $L D L$. 


\subsection{SNP-Based Phylogenetic Relationships of the Strains}

The SNP-based analysis revealed that the $L D B$ strains were all phylogenetically distinct (Figure 1). The closest pairs of strains displayed 34 (CIRM BIA 1379 and CIRM BIA 1581) and 94 (CIRM BIA 864 and CIRM BIA 1623) SNPs. As the origins of these isolates were different, they were considered closely related but different strains.

Tree scale: 0.01

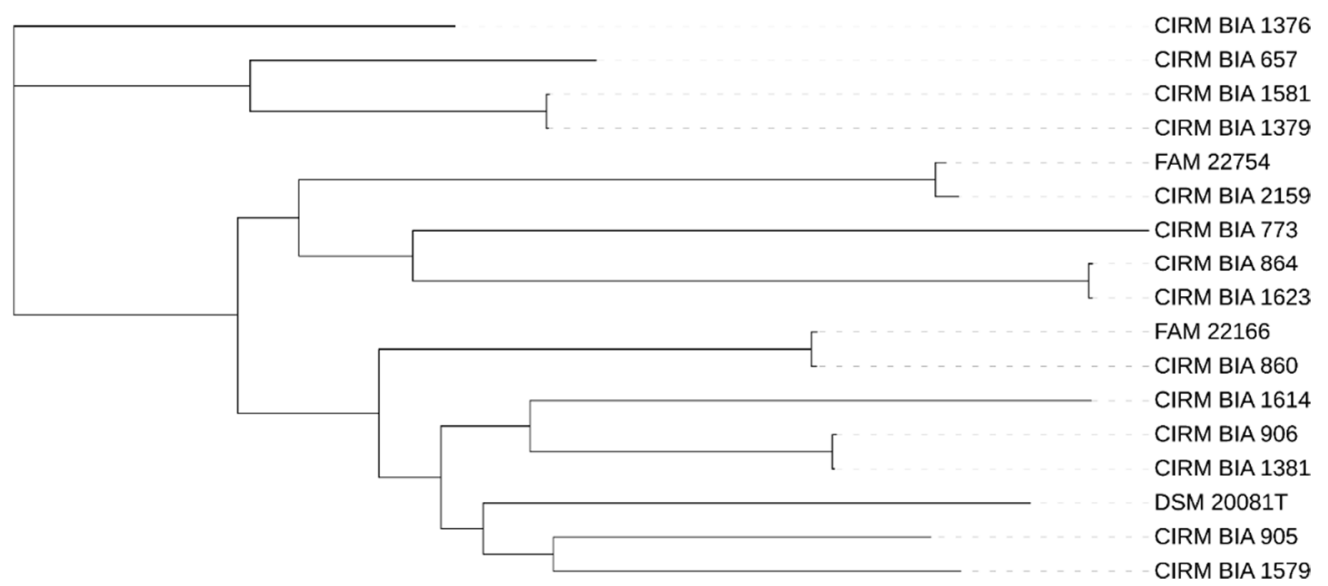

Figure 1. SNP-based phylogenetic tree of Lactobacillus delbrueckii subsp. bulgaricus strains assessed in this study. The scale shows the rate of single nucleotide polymorphisms.

A more complex pattern was obtained for the $L D L$ strains (Figure 2). Twenty-eight strains formed a homogeneous phylogenetic group. All pairs of strains in this group, however, displayed more than 120 SNPs (median 1067 SNPs). All but one (CIRM BIA 1375) were isolated from Swiss dairy products, mainly from cheese or from undefined mixed starter cultures, mostly obtained from different cheese factories. Several other groups consisted of similar, though different, strains: FAM 1200, FAM 22091, FAM 22092, FAM 22093, FAM 22274, and FAM 22680 displayed more than 368 SNPs. These strains were isolated from Swiss whey (no information available for FAM 1200). NCIMB 700820 and NCIMB 700860 displayed more than 2000 SNPs. Both CIRM BIA 230 and CIRM BIA 265 were isolated from Finnish Emmental cheese in 1968, but they were considered different strains, as they displayed 138 SNPs. CIRM BIA 233 and CIRM BIA 234 were both isolated from a French yogurt factory in 1984, and they displayed 12 SNPs. Given the strong suspicion that they belong to the same strain, CIRM BIA 234 was not included in the antibiotic susceptibility profiles. CIRM BIA 269 displayed 12 SNPs when compared with CIRM BIA 233 and CIRM BIA 234, but it was still regarded as a different strain given its different origin. CIRM BIA 267 had the same origin as CIRM BIA 269, but these isolates displayed more than 150 SNPs. NCIMB 8183, NCIMB 8964, DSM 20355, DSM 20073, and DSM 20076 all displayed more than 100 SNPs. NCIMB 7278 and NCIMB 701437 displayed 36 SNPs. As information about their origin was unavailable, they were considered identical, and only NCIMB 701437 was included in the antibiotic susceptibility profiles. NCIMB 8011 and NCIMB 8170, although considerably closely related to NCIMB 701437, were still considered different strains, as they displayed more than 50 SNPs with respect to the latter strain and between each other. Finally, FAM 24849, FAM 24850, and FAM 24852 all displayed fewer than $12 \mathrm{SNPs}$. As these strains were isolated from different commercial starter cultures but from the same company, there is a high probability that the same strain was used in all three starter cultures. Therefore, only FAM 24850 was included in the susceptibility profiles. 


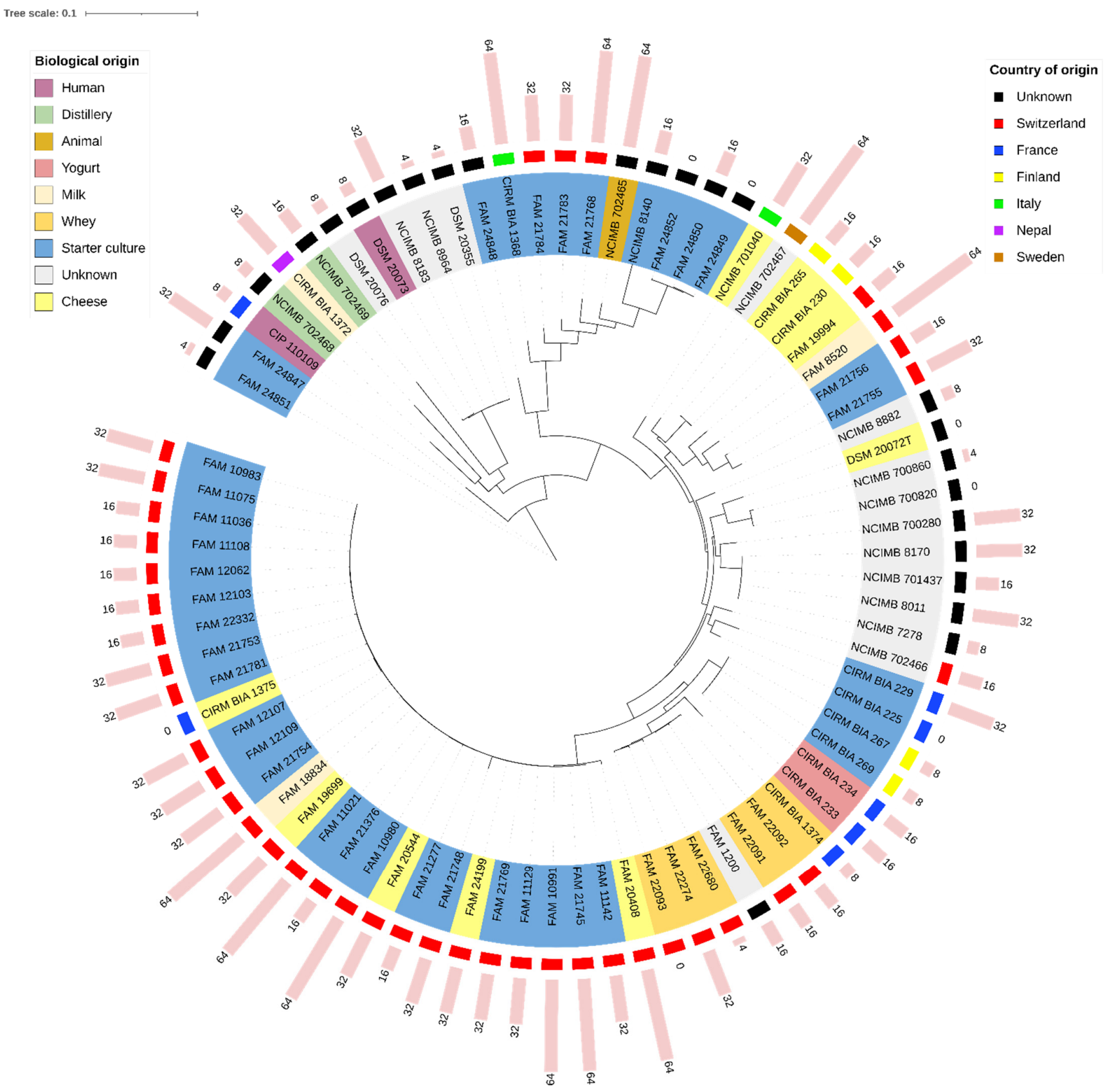

Figure 2. SNP-based phylogenetic tree of the Lactobacillus delbrueckii subsp. lactis strains assessed in this study. Country and biological origin, as well as the defined minimal inhibitory concentration of kanamycin (MICs, pink bars, along with their numerical values expressed in $\mathrm{mg} / \mathrm{L}$ ) are displayed. For strains that did not grow in the test medium or that have not been tested, MIC of kanamycin is indicated with ' 0 '. The scale shows the rate of single nucleotide polymorphisms.

\subsection{ARGs in the Genome Assemblies}

The search for ARGs in the strain assemblies revealed a single match, namely strain FAM 22754. In the assembly of this strain, an ermB gene was detected in a small, low coverage, scaffold $(763 \mathrm{bp})$. To confirm/infirm the presence of this gene in the strain FAM 22754, we performed a specific PCR targeting ermB, as described previously [50]. The presence of ermB could neither be confirmed using the DNA extracts used for sequencing, nor using new DNA extracts from the strain, and we concluded that its presence in the assembly was due to a contamination during DNA extraction, library preparation, or sequencing. 


\subsection{Antibiotic Susceptibility Profiles and Determination of MCs}

Six strains (five $L D L$ and one $L D B$ ) did not grow in the test medium (i.e., LSM): FAM 22093, CIRM BIA 225, NCIMB 700820, CIRM BIA 1375, DSM $20072^{\mathrm{T}}$ and CIRM BIA 1381. Thus, they were excluded from subsequent analyses.

Among the 90 remaining L. delbrueckii strains, 42 (46.7\%) displayed MICs higher than the FEEDAP MC for KAN, eight (8.9\%) for CHL, four (4.4\%) for TET, and one $(1.1 \%)$ each for VAN, STR, and ERY (Table 3, Figure 3). The MCs for all the investigated subspecies were higher than the FEEDAP MCs for KAN (256 mg/L instead of $16 \mathrm{mg} / \mathrm{L}$ ), TET $(16 \mathrm{mg} / \mathrm{L}$ instead of $4 \mathrm{mg} / \mathrm{L})$, and CHL ( $8 \mathrm{mg} / \mathrm{L}$ instead of $4 \mathrm{mg} / \mathrm{L})$.
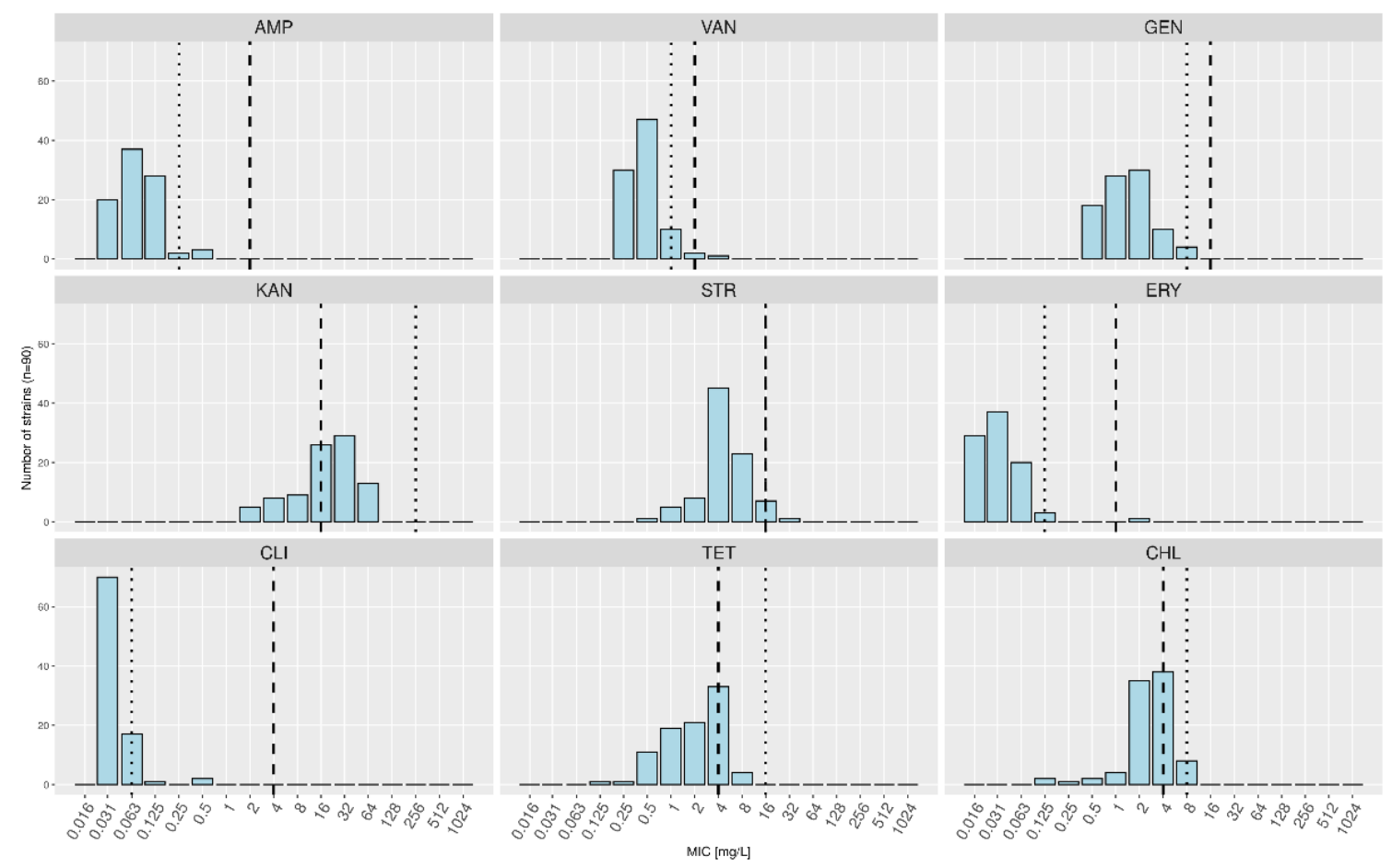

Figure 3. Combined minimal inhibitory concentration (MIC) distributions for Lactobacillus delbrueckii subsp. lactis and L. delbrueckii subsp. bulgaricus. The dashed lines indicate the current microbiological cutoffs (MCs) as defined by the European Food Safety Authority, and the dotted lines represent the calculated MCs based on the MICs measured in this study.

As for LDL (Table 3, Figure 4), 37 strains out of 71 (52.1\%) displayed MICs higher than the FEEDAP MC for KAN, seven (9.9\%) for CHL, four (5.6\%) for TET, and one $(1.4 \%)$ each for VAN and STR. The MCs calculated based solely on this subspecies were higher than the FEEDAP MCs for KAN (128 mg/L instead of $16 \mathrm{mg} / \mathrm{L})$, TET $(16 \mathrm{mg} / \mathrm{L}$ instead of $4 \mathrm{mg} / \mathrm{L})$, and CHL (16 mg/L instead of $4 \mathrm{mg} / \mathrm{L})$. Conversely, MCs were lower for AMP $(0.25 \mathrm{mg} / \mathrm{L}$ instead of $2 \mathrm{mg} / \mathrm{L}), \mathrm{GEN}(8 \mathrm{mg} / \mathrm{L}$ instead of $16 \mathrm{mg} / \mathrm{L})$, ERY $(0.125 \mathrm{mg} / \mathrm{L}$ instead of $1 \mathrm{mg} / \mathrm{L})$, CLI $(0.125 \mathrm{mg} / \mathrm{L}$ instead of $4 \mathrm{mg} / \mathrm{L})$, and VAN $(1 \mathrm{mg} / \mathrm{L}$ instead of $2 \mathrm{mg} / \mathrm{L})$. 


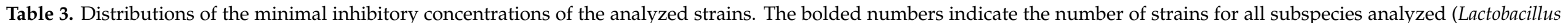

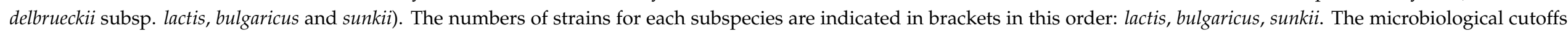

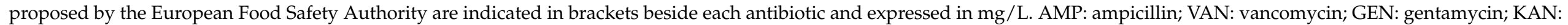
kanamycin; STR: streptomycin; ERY: erythromycin; CLI: clindamycin; TET: tetracycline; CHL: chloramphenicol.

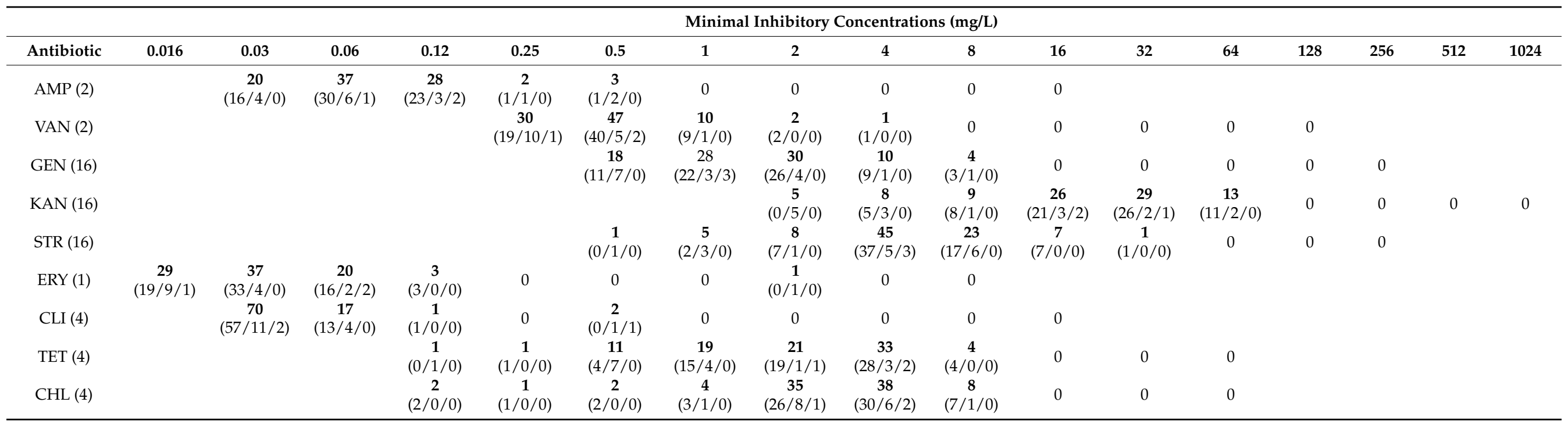



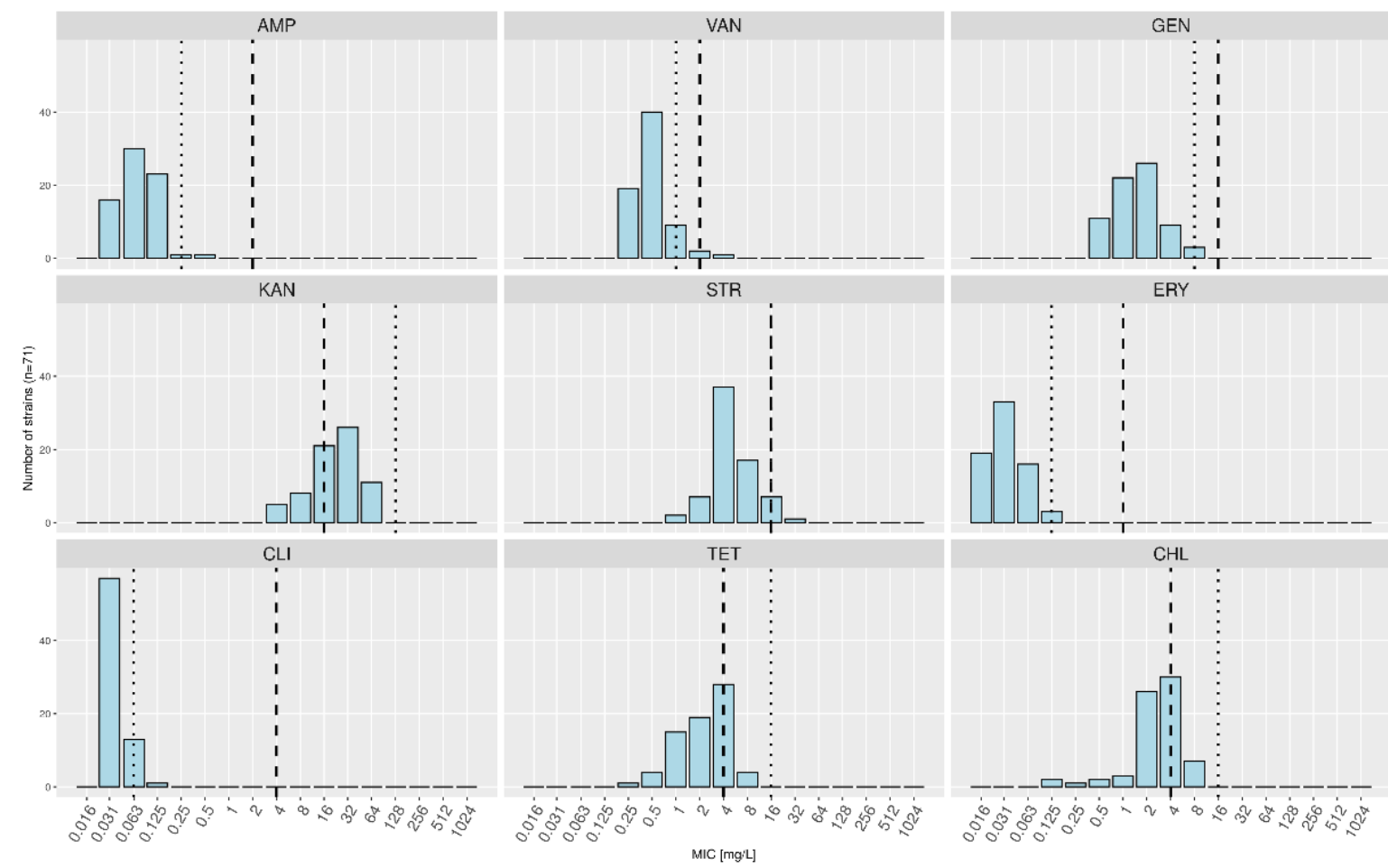

Figure 4. Minimal inhibitory concentration (MIC) distributions for Lactobacillus delbrueckii subsp. lactis only. The dashed lines indicate the current microbiological cutoffs (MCs) as defined by the European Food Safety Authority, and the dotted lines represent the calculated MCs based on the MICs measured in this study.

No link could be drawn between the levels of resistance to antibiotics and the origins of the strains or their position in the SNP-based phylogenetic tree (Figure 2).

\section{Discussion}

Used alongside S. salivarius subsp. thermophilus, $L D L$ is the major L. delbrueckii subspecies added as a thermophilic starter in the production of cooked Swiss cheese varieties. The development of starter or adjunct cultures for the cheese market involves a thorough screening of strain characteristics. MIC values determined through broth microdilution testing are commonly used as an easy criterion for the early acceptance or rejection of candidate strains prior to the in-depth characterization of their properties to determine their suitability for cheese production. In the case of $L D L$, the ABR status of new candidates is often subject to debate, as values regularly exceed the defined FEEDAP MCs, particularly that for KAN (Agroscope, data not shown). The FEEDAP MCs have been defined for the entire group of obligate homofermentative lactobacilli, consisting of at least 31 species [18]. Here, we questioned the relevance of the current FEEDAP MCs for L. delbrueckii, more specifically for $L D L$.

An unambiguous identification of a strain is a prerequisite for any further safety assessment [17]. Controlling the taxonomic affiliation of our strain assortment led to the re-assignment of one and five strains at the species and subspecies levels, respectively. In addition, during the preliminary selection of strains suitable for this study, six strains in the Agroscope Culture Collection were taxonomically re-assigned at the subspecies level (data not shown). Here, we assessed the taxonomic affiliation at the subspecies level based on the ANI values. According to previous research, strains whose genomes display an ANI of $\geq 96.5 \%$ and an alignment fraction of $\geq 0.6$ can be grouped into a single species [51]. At the subspecies level, however, no similar cutoffs have been defined. We therefore assessed visually the positions of the strains and their similarities in the ANI- 
based tree relative to different type strains. The subspecies of strains in some culture collections have often been defined based solely on physiological properties, and modern molecular techniques have not been systematically applied. Today, as NGS has become an affordable approach, taxonomic affiliations can be reassessed in the light of whole genome comparisons. Considering the taxonomic assessment performed here and the subsequent re-classifications, we strongly recommend that the taxonomic affiliation of the examined strains, even those deposited in culture collections, be systematically questioned. Comparisons at the genomic level are a good approach; however, more rapid methods that require less computational analysis (e.g., MALDI-TOF) may also provide a good evaluation of certain taxa. In our study, MALDI-TOF allowed for the discrimination of $L D L$ and $L D B$, but not of $L D S$, as this subspecies is not yet referenced in the BDAL v11.0 library used here.

Most strains selected for analysis in our study were dairy isolates (obtained from milk, dairy products, natural whey, and other starter cultures) from Switzerland, as most strains were provided by the Agroscope Culture Collection, which includes strains mainly obtained from Swiss dairy products. To determine the MICs of the non-dairy isolates, we broadened the range of origins by including strains obtained from other habitats, such as human saliva, calf stomachs, or distilleries. Moreover, care was taken in expanding the strain selection to include those obtained from heterogeneous dairy products and those with different geographical origins. Furthermore, the selected strains were isolated within a period covering at least 69 years (1950-2019), within which the golden age of antibiotics and the subsequent dissemination of ABR determinants is included [52]. On the one hand, our strain selection allowed to avoid potential habitat-related biases. Although strains in some environments may be more exposed to selective pressure exerted by antibiotics or other antimicrobials, the spread of ABR is less likely to occur between habitats than within a single habitat $[53,54]$. Therefore, the overall elevated resistance towards KAN observed here is most likely an intrinsic characteristic of L. delbrueckii rather than a resistance that has been transmitted across habitats and time. On the other hand, selecting strains of different origins increases the chance of getting as many different strains as possible.

MCs were calculated using MIC distributions based on the susceptibility profiles of distinct strains. Here, potential duplicate strains were discarded after empirically examining the strains' relationships in a SNP-based phylogenetic tree and after determining the number of SNPs between pairs of strains. This step is crucial to avoid duplicated MIC results that would lead to biased MIC distributions. The number of SNPs below which two strains were considered identical was defined subjectively based on previous SNPs analyses of different strains (data not shown) and may be adapted. Although the use of SNPs alone to discriminate between different strains is not standard, the threshold defined in this study is relatively consistent with results of other studies investigating clinical isolates [55-57]. Furthermore, the defined threshold of 50 SNPs appears reasonable considering the origins of the analyzed strains.

No association between the origins of the strains and their antimicrobial susceptibility patterns could be evidenced, suggesting that no particular antibiotic susceptibilities were selected in various ecological niches. Similarly, no link could be drawn between the year of isolation and the antimicrobial susceptibility patterns, suggesting that the selection pressure exerted by antibiotics used in veterinary medicine and farming towards L. delbrueckii has remained relatively moderate.

In this study, we postulated that the observed phenotypic resistances in $L D L$ are actually false positives due to the inaccurate MCs. Our results tend to confirm our hypothesis. Indeed, although more than half of the tested $L D L$ strains were phenotypically defined as 'resistant' to KAN according to the FEEDAP criteria, none of them displayed any known ARG. Similar observations were previously reported, with, e.g., $25 \%$ of tested $L D B$ having MICs of KAN above the EFSA MC but no detected ARG [58]. The proportion of L. delbrueckii strains with MICs above the MCs for chloramphenicol (8.9\%) in our study is higher than previously reported $[58,59]$. Conversely, the proportion of TET-resistant strains was lower in our study (4.4\%) than in a previous study carried out on $11 \mathrm{~L}$. delbrueckii 
strains [59]. The range of MICs of TET seems to be relatively broad by L. delbrueckii, as shown here, but also considering results from other studies. Indeed, the proportion of TET-resistant strains found here was lower (4.4\%) than in a previous study carried out on 11 L. delbrueckii strains [59] but higher than in another one based on 4 LDL strains from natural whey starters, where no resistance to GEN, ERY, TET, and VAN was detected [60]. In addition to the fact that we detected no ARGs, all MIC distributions of $L D L$ were unimodal, while a bimodal distribution would be expected in case of an acquired antibiotic resistance. On the other hand, the high susceptibilities to AMP, ERY, and CLI observed in most of our investigated strains represent a common feature of Lactobacillus delbrueckii that has already been reported by others $[58,59,61]$. For these three antibiotics, it rather seems that the MCs have been defined too high, which may open the door to false negative results and consequently the potential introduction of antibiotic resistant strains into the food chain.

Based on our observations, we therefore conclude that the MCs defined for the entire group of homofermentative lactobacilli should be redefined at the species or even at the subspecies level. Our strain selection may be too narrow in order that new MCs could be proposed for the entire species, as we have not tested some of the subspecies for their antimicrobial susceptibilities ( $L D D, L D I$, and $L D J)$. However, our calculations based on strains of the subspecies bulgaricus, lactis, and sunkii suggest that the MCs for KAN, TET and CHL for L. delbrueckii should be increased, whereas the MCs for AMP, ERY and CLI should be decreased. For $L D L$, we suggest that the MCs for KAN, TET and CHL be increased to at least 128,16 , and $16 \mathrm{mg} / \mathrm{L}$, respectively. Conversely, the MCs for AMP, ERY and CLI could be reduced to $0.25,0.125$, and $0.063 \mathrm{mg} / \mathrm{L}$, respectively.

Recently, Stefanska et al. detected $32 \%$ of KAN-resistant strains in a wider range of LAB species using broth microdilution [62]. Of these strains, only three $(4.6 \%)$ carried $\operatorname{aph}\left(3^{\prime \prime}\right)-I I I a$, a gene conferring resistance to this antibiotic. The issue raised in our study and that has already been reported for other species may thus be widespread in other LAB species, too $[19,23]$.

The facts that a non-negligible number of strains were unable to grow in the test medium and that some variations occur in the phenotypic measures support the dual approach proposed by the FEEDAP, that is, phenotypic testing complemented by a search of the WGS for known ARGs [17]. The phenotypic approach may allow for the detection of yet unknown ABR mechanisms and is relatively advantageous in terms of cost and time. It can thus be used as a primary screening approach, along with the use of accurate MCs to avoid false positives that may drastically reduce the number of candidates [19]. Meanwhile, the WGS approach provides an appropriate method to evaluate strains that do not grow on test media and to confirm the resistances observed using the phenotypic test.

Supplementary Materials: The following are available online at https:/ / www.mdpi.com/article / 10.3390 / foods10123145/s1, Figure S1: Average Nucleotide Identities of the Lactobacillus delbrueckii strains.

Author Contributions: Conceptualization: N.S. and H.-P.B.; formal analysis: N.S. and S.O.; writingoriginal draft preparation: N.S. and H.-P.B.; writing-review and editing: H.-P.B., R.S.S., H.B. and S.O.; supervision: H.-P.B. and H.B.; resources: H.B. and R.S.S.; funding acquisition: H.-P.B. and R.S.S. All authors have read and agreed to the published version of the manuscript.

Funding: This research received no external funding.

Institutional Review Board Statement: Not applicable.

Informed Consent Statement: Not applicable.

Data Availability Statement: Publicly available datasets were analyzed in this study. Genomic data generated in this study have been deposited at GenBank under BioProject PRJNA777018 with GenBank WGS accessions JAJNSH000000000-JAJNVX000000000. Other publicly available genomic data analysed in this study can be found at GenBank under following Genbank WGS accessions: GCA_005864055.1, GCA_005864125.1, GCA_002278095.1, GCA_000056065.1, GCA_001888965.1, GCA_001908495.1,GCA_001888965.1,GCA_001908415.1,GCA_001888925.1, and GCA_009789085.1. 
Acknowledgments: We thank the Next Generation Sequencing Platform, University of Bern, for performing the high-throughput sequencing experiments and the Culture Collection of Switzerland (CCOS) for the antibiotic susceptibility testing experiments. We also thank Daniel Marzohl and Pascal Bätscher for their valuable technical help.

Conflicts of Interest: The authors declare no conflict of interest. The funders had no role in designing this study; in the collection, analyses, or interpretation of data; in manuscript writing; or in the decision to publish the results.

\section{References}

1. Bourdichon, F.; Alper, I.; Bibiloni, R.; Dubois, A.; Laulund, S.; Miks, M.; Morelli, L.; Yao, S. Inventory of Microbial Food Cultures with Safety Demonstration in Fermented Food Products; Update of the Bulletin of the IDF 455-2012; Bulletin of the International Dairy Federation: Brussels, Belgium, 2018; Volume 495, pp. 1-74.

2. $\quad$ El Kafsi, H.; Binesse, J.; Loux, V.; Buratti, J.; Boudebbouze, S.; Dervyn, R.; Kennedy, S.; Galleron, N.; Quinquis, B.; Batto, J.-M.; et al. Lactobacillus delbrueckii ssp. lactis and ssp. bulgaricus: A chronicle of evolution in action. BMC Genom. 2014, 15, 1-12. [CrossRef]

3. Sieuwerts, S.; de Bok, F.A.M.; Hugenholtz, J.; van Hylckama Vlieg, J.E.T. Unraveling Microbial Interactions in Food Fermentations: From Classical to Genomics Approaches. Appl. Environ. Microbiol. 2008, 74, 4997-5007. [CrossRef] [PubMed]

4. Somerville, V.; Berthoud, H.; Schmidt, R.S.; Bachmann, H.-P.; Meng, Y.H.; Fuchsmann, P.; von Ah, U.; Engel, P. Functional strain redundancy and persistent phage infection in Swiss hard cheese starter cultures. ISME J. 2021, 1-12. [CrossRef]

5. Schmid, M.; Muri, J.; Melidis, D.; Varadarajan, A.R.; Somerville, V.; Wicki, A.; Moser, A.; Bourqui, M.; Wenzel, C.; Eugster-Meier, E.; et al. Comparative Genomics of Completely Sequenced Lactobacillus helveticus Genomes Provides Insights into Strain-Specific Genes and Resolves Metagenomics Data Down to the Strain Level. Front. Microbiol. 2018, 9, 63. [CrossRef]

6. Gobbetti, M.; Di Cagno, R.; Calasso, M.; Neviani, E.; Fox, P.F.; De Angelis, M. Drivers that establish and assembly the lactic acid bacteria biota in cheeses. Trends Food Sci. Technol. 2018, 78, 244-254. [CrossRef]

7. Ghosh, T.; Beniwal, A.; Semwal, A.; Navani, N.K. Mechanistic insights into probiotic properties of lactic acid bacteria associated with ethnic fermented dairy products. Front. Microbiol. 2019, 10, 1-19. [CrossRef]

8. Liu, M.; Bayjanov, J.R.; Renckens, B.; Nauta, A.; Siezen, R.J. The proteolytic system of lactic acid bacteria revisited: A genomic comparison. BMC Genom. 2010, 11, 36. [CrossRef] [PubMed]

9. Parente, E.; Cogan, T.M.; Powell, I. Starter cultures: General aspects, chemistry, physics and microbiology. In Cheese, 4th ed.; McSweeney, P.L.H., Fox, P.F., Cotter, P.D., Everett, D.W., Eds.; Academic Press: London, UK, 2017; pp. 201-226. [CrossRef]

10. European Food Safety Authority Panel on Biological Hazards (BIOHAZ); Koutsoumanis, K.; Allende, A.; Alvarez-Ordóñez, A.; Bolton, D.; Bover-Cid, S.; Chemaly, M.; Davies, R.; De Cesare, A.; Hilbert, F.; et al. Update of the list of QPS-recommended biological agents intentionally added to food or feed as notified to EFSA 14: Suitability of taxonomic units notified to EFSA until March 2021. EFSA J. 2021, 19, e06689. [CrossRef] [PubMed]

11. European Food Safety Authority Panel on Biological Hazards (BIOHAZ); Andreoletti, O.; Budka, H.; Buncic, S.; Colin, P.; Collins, J.D.; De Koeijer, A.; Griffin, J.; Havelaar, A.; Hope, J.; et al. The maintenance of the list of QPS microorganisms intentionally added to food or feed-scientific opinion of the Panel on Biological Hazards. EFSA J. 2008, 6, 923. [CrossRef]

12. Ben, Y.; Fu, C.; Hu, M.; Liu, L.; Wong, M.H.; Zheng, C. Human health risk assessment of antibiotic resistance associated with antibiotic residues in the environment: A review. Environ. Res. 2018, 169, 483-493. [CrossRef] [PubMed]

13. Huddleston, J.R. Horizontal gene transfer in the human gastrointestinal tract: Potential spread of antibiotic resistance genes. Infect. Drug Resist. 2014, 7, 167-176. [CrossRef]

14. Lerner, A.; Matthias, T.; Aminov, R. Potential Effects of Horizontal Gene Exchange in the Human Gut. Front. Immunol. 2017, 8, 1630. [CrossRef]

15. Thumu, S.C.R.; Halami, P.M. Conjugal transfer of erm(B) and multiple tet genes from Lactobacillus spp. to bacterial pathogens in animal gut, in vitro and during food fermentation. Food Res. Int. 2018, 116, 1066-1075. [CrossRef]

16. Herman, L.; Chemaly, M.; Cocconcelli, P.S.; Fernandez, P.; Klein, G.; Peixe, L.; Prieto, M.; Querol, A.; Suarez, J.E.; Sundh, I.; et al. The qualified presumption of safety assessment and its role in EFSA risk evaluations: 15 years past. FEMS Microbiol. Lett. 2018, 366. [CrossRef]

17. European Food Safety Authority Panel on Additives and Products or Substances used in Animal Feed (FEEDAP); Rychen, G.; Aquilina, G.; Azimonti, G.; Bampidis, V.; Bastos, M.d.L.; Bories, G.; Chesson, A.; Cocconcelli, P.S.; Flachowsky, G.; et al. Guidance on the characterisation of microorganisms used as feed additives or as production organisms. EFSA J. 2018, $16,5206$.

18. Hammes, W.P.; Hertel, C. Lactobacillus. In Bergey's Manual of Systematics of Archaea and Bacteria; Whitman, W.B., DeVos, P., Dedysh, S., Hedlund, B., Kämpfer, P., Rainey, F., Trujillo, M.E., Bowman, J.P., Brown, D.R., Glöckner, F.O., et al., Eds.; John Wiley \& Sons, Inc.: Hoboken, NJ, USA, Bergey's Manual Trust: New York, NY, USA, 2015; pp. 1-76.

19. Shani, N.; Oberhaensli, S.; Arias-Roth, E. Antibiotic Susceptibility Profiles of Pediococcus pentosaceus from Various Origins and Their Implications for the Safety Assessment of Strains with Food-Technology Applications. J. Food Prot. 2020, 84, 1160-1168. [CrossRef] [PubMed]

20. Ashaolu, T.J.; Reale, A. A Holistic Review on Euro-Asian Lactic Acid Bacteria Fermented Cereals and Vegetables. Microorganisms 2020, 8, 1176. [CrossRef] 
21. Tamang, J.P.; Watanabe, K.; Holzapfel, W.H. Review: Diversity of Microorganisms in Global Fermented Foods and Beverages. Front. Microbiol. 2016, 7, 377. [CrossRef]

22. De Man, J.C.; Rogosa, M.; Sharpe, M.E. A Medium for the Cultivation of Lactobacilli. J. Appl. Bacteriol. 1960, $23,130-135$. [CrossRef]

23. Lüdin, P.; Roetschi, A.; Wüthrich, D.; Bruggmann, R.; Berthoud, H.; Shani, N. Update on Tetracycline Susceptibility of Pediococcus acidilactici Based on Strains Isolated from Swiss Cheese and Whey. J. Food Prot. 2018, 81, 1582-1589. [CrossRef]

24. Dreier, M.; Berthoud, H.; Shani, N.; Wechsler, D.; Junier, P. SpeciesPrimer: A bioinformatics pipeline dedicated to the design of qPCR primers for the quantification of bacterial species. PeerJ 2020, 8, e8544. [CrossRef]

25. Low, A.J.; Koziol, A.G.; Manninger, P.A.; Blais, B.; Carrillo, C.D. ConFindr: Rapid detection of intraspecies and cross-species contamination in bacterial whole-genome sequence data. PeerJ 2019, 7, e6995. [CrossRef]

26. Andrews, S. FastQC: A Quality Control Tool for High Throughput Sequence Data. 2010. Available online: http://www. bioinformatics.babraham.ac.uk/projects/fastqc/ (accessed on 1 June 2021).

27. Chen, S.; Zhou, Y.; Chen, Y.; Gu, J. fastp: An ultra-fast all-in-one FASTQ preprocessor. Bioinformatics 2018, 34, i884-i890. [CrossRef] [PubMed]

28. Bankevich, A.; Nurk, S.; Antipov, D.; Gurevich, A.A.; Dvorkin, M.; Kulikov, A.S.; Lesin, V.M.; Nikolenko, S.I.; Pham, S.; Prjibelski, A.D.; et al. SPAdes: A new genome assembly algorithm and its applications to single-cell sequencing. J. Comput. Biol. 2012, 19, 455-477. [CrossRef] [PubMed]

29. Gurevich, A.; Saveliev, V.; Vyahhi, N.; Tesler, G. QUAST: Quality assessment tool for genome assemblies. Bioinformatics 2013, 29, 1072-1075. [CrossRef] [PubMed]

30. Seppey, M.; Manni, M.; Zdobnov, E.M. BUSCO: Assessing Genome Assembly and Annotation Completeness. In Gene Prediction; Kollmar, M., Ed.; Methods in Molecular Biology; Humana: New York, NY, USA, 2019; Volume 1962, pp. $227-245$.

31. Jain, C.; Rodriguez-R, L.M.; Phillippy, A.M.; Konstantinidis, K.T.; Aluru, S. High throughput ANI analysis of 90K prokaryotic genomes reveals clear species boundaries. Nat. Commun. 2018, 9, 5114. [CrossRef]

32. Warnes, G.R.; Bolker, B.; Bonebakker, L.; Gentleman, R.; Huber, W.; Liaw, A.; Lumley, T.; Maechler, M.; Magnusson, A.; Moeller, S.; et al. gplots: Various R Programming Tools for Plotting Data. Available online: https:/ /CRAN.R-project.org/package=gplots (accessed on 12 October 2021).

33. R StudioTeam. RStudio: Integrated Development for R; RStudio, PBC: Boston, MA, USA, 2020; Available online: http://www. rstudio.com/ (accessed on 12 October 2021).

34. R Core Team. R: A Language and Environment for Statistical Computing; R Foundation for Statistical Computing: Vienna, Austria, 2020; Available online: https: / / www.R-project.org/ (accessed on 12 October 2021).

35. Shakya, M.; Ahmed, S.A.; Davenport, K.W.; Flynn, M.C.; Lo, C.-C.; Chain, P.S.G. Standardized phylogenetic and molecular evolutionary analysis applied to species across the microbial tree of life. Sci. Rep. 2020, 10, 1-15. [CrossRef]

36. Minh, B.Q.; Schmidt, H.A.; Chernomor, O.; Schrempf, D.; Woodhams, M.D.; von Haeseler, A.; Lanfear, R. IQ-TREE 2: New Models and Efficient Methods for Phylogenetic Inference in the Genomic Era. Mol. Biol. Evol. 2020, 37, 1530-1534. [CrossRef]

37. Letunic, I.; Bork, P. Interactive Tree of Life (iTOL) v5: An online tool for phylogenetic tree display and annotation. Nucleic Acids Res. 2021, 49, W293-W296. [CrossRef] [PubMed]

38. Dijkshoorn, L.; Ursing, B.; Ursing, J. Strain, clone and species: Comments on three basic concepts of bacteriology. J. Med Microbiol. 2000, 49, 397-401. [CrossRef] [PubMed]

39. Seemann, T. Abricate. 2020. Available online: https://github.com/tseemann/abricate (accessed on 25 February 2020).

40. Feldgarden, M.; Brover, V.; Haft, D.H.; Prasad, A.B.; Slotta, D.J.; Tolstoy, I.; Tyson, G.H.; Zhao, S.; Hsu, C.-H.; McDermott, P.F.; et al. Validating the AMRFinder Tool and Resistance Gene Database by Using Antimicrobial Resistance Genotype-Phenotype Correlations in a Collection of Isolates. Antimicrob. Agents Chemother. 2019, 63. [CrossRef]

41. Jia, B.; Raphenya, A.R.; Alcock, B.; Waglechner, N.; Guo, P.; Tsang, K.K.; Lago, B.A.; Dave, B.M.; Pereira, S.; Sharma, A.N.; et al. CARD 2017: Expansion and model-centric curation of the comprehensive antibiotic resistance database. Nucleic Acids Res. 2017, 45, D566-D573. [CrossRef]

42. McArthur, A.G.; Waglechner, N.; Nizam, F.; Yan, A.; Azad, M.A.; Baylay, A.J.; Bhullar, K.; Canova, M.J.; De Pascale, G.; Ejim, L.; et al. The Comprehensive Antibiotic Resistance Database. Antimicrob. Agents Chemother. 2013, 57, 3348-3357. [CrossRef]

43. Gupta, S.; Padmanabhan, B.R.; Diene, S.M.; Lopez-Rojas, R.; Kempf, M.; Landraud, L.; Rolain, J.-M. ARG-ANNOT, a New Bioinformatic Tool to Discover Antibiotic Resistance Genes in Bacterial Genomes. Antimicrob. Agents Chemother. 2013, 58, 212-220. [CrossRef]

44. Zankari, E.; Hasman, H.; Cosentino, S.; Vestergaard, M.; Rasmussen, S.; Lund, O.; Aarestrup, F.M.; Larsen, M.V. Identification of acquired antimicrobial resistance genes. J. Antimicrob. Chemother. 2012, 67, 2640-2644. [CrossRef]

45. The European Committee on Antimicrobial Susceptibility Testing. Breakpoint Tables for Interpretation of MICs and Zone Diameters. Version 11.0. 2021. Available online: http:/ / www.eucast.org (accessed on 28 July 2021).

46. International Organization for Standardization (ISO). Milk and Milk Products—Determination of the Minimal Inhibitory Concentration (MIC) of Antibiotics Applicable to Bifidobacteria and Non-Enterococcal Lactic Acid Bacteria (LAB); ISO 10932 I IDF 223:2010; International Organization for Standardization: Geneva, Switzerland, 2010. 
47. Klare, I.; Konstabel, C.; Müller-Bertling, S.; Reissbrodt, R.; Huys, G.; Vancanneyt, M.; Swings, J.; Goossens, H.; Witte, W. Evaluation of New Broth Media for Microdilution Antibiotic Susceptibility Testing of Lactobacilli, Pediococci, Lactococci, and Bifidobacteria. Appl. Environ. Microbiol. 2005, 71. [CrossRef] [PubMed]

48. Turnidge, J.; Kahlmeter, G.; Kronvall, G. Statistical characterisation of bacterial wild-type MIC value distributions and the determination of epidemiological cut-off values. Clin. Microbiol. Infect. 2006, 12, 418-425. [CrossRef] [PubMed]

49. Wickham, H. ggplot2: Elegant Graphics for Data Analysis, 2nd ed.; Springer International Publishing: New York, NY, USA, 2016.

50. Böckelmann, U.; Dörries, H.-H.; Ayuso-Gabella, M.N.; de Marçay, M.S.; Tandoi, V.; Levantesi, C.; Masciopinto, C.; Van Houtte, E.; Szewzyk, U.; Wintgens, T.; et al. Quantitative PCR Monitoring of Antibiotic Resistance Genes and Bacterial Pathogens in Three European Artificial Groundwater Recharge Systems. Appl. Environ. Microbiol. 2009, 75, 154-163. [CrossRef] [PubMed]

51. Varghese, N.J.; Mukherjee, S.; Ivanova, N.; Konstantinidis, K.T.; Mavrommatis, K.; Kyrpides, N.C.; Pati, A. Microbial species delineation using whole genome sequences. Nucleic Acids Res. 2015, 43, 6761-6771. [CrossRef]

52. Davies, J.; Davies, D. Origins and Evolution of Antibiotic Resistance. Microbiol. Mol. Biol. Rev. 2010, 74, 417-433. [CrossRef] [PubMed]

53. Martinez, J.L.; Coque, T.M.; Baquero, F. What is a resistance gene? Ranking risk in resistomes. Nat. Rev. Genet. 2014, 13, 116-123. [CrossRef]

54. Pal, C.; Bengtsson-Palme, J.; Kristiansson, E.; Larsson, D.G.J. The structure and diversity of human, animal and environmental resistomes. Microbiome 2016, 4, 54. [CrossRef] [PubMed]

55. Ksibi, B.; Ktari, S.; Othman, H.; Ghedira, K.; Maalej, S.; Mnif, B.; Abbassi, M.S.; Fabre, L.; Rhimi, F.; Le Hello, S.; et al. Comparison of conventional molecular and whole-genome sequencing methods for subtyping Salmonella enterica serovar Enteritidis strains from Tunisia. Eur. J. Clin. Microbiol. Infect. Dis. 2020, 40, 597-606. [CrossRef]

56. Schürch, A.; Arredondo-Alonso, S.; Willems, R.; Goering, R. Whole genome sequencing options for bacterial strain typing and epidemiologic analysis based on single nucleotide polymorphism versus gene-by-gene-based approaches. Clin. Microbiol. Infect. 2018, 24, 350-354. [CrossRef]

57. Taylor, A.J.; Lappi, V.; Wolfgang, W.J.; Lapierre, P.; Palumbo, M.J.; Medus, C.; Boxrud, D. Characterization of Foodborne Outbreaks of Salmonella enterica Serovar Enteritidis with Whole-Genome Sequencing Single Nucleotide Polymorphism-Based Analysis for Surveillance and Outbreak Detection. J. Clin. Microbiol. 2015, 53, 3334-3340. [CrossRef] [PubMed]

58. Guo, H.; Zhang, W.; Kwok, L.-Y.; Menghe, B. In vitro evalution of antibiotic resistance of Lactobacillus bulgaricus strains isolated from traditional dairy products. Czech J. Food Sci. 2019, 37, 36-43. [CrossRef]

59. Cho, G.-S.; Cappello, C.; Schrader, K.; Fagbemigum, O.; Oguntoyinbo, F.A.; Csovcsics, C.; Sch, N.R.; Kabisch, J.; Neve, H.; Bockelmann, W.; et al. Isolation and Characterization of Lactic Acid Bacteria from Fermented Goat Milk in Tajikistan. J. Microbiol. Biotechnol. 2018, 28, 1834-1845. [CrossRef]

60. Rossetti, L.; Carminati, D.; Zago, M.; Giraffa, G. A Qualified Presumption of Safety approach for the safety assessment of Grana Padano whey starters. Int. J. Food Microbiol. 2009, 130, 70-73. [CrossRef]

61. D'Aimmo, M.R.; Modesto, M.; Biavati, B. Antibiotic resistance of lactic acid bacteria and Bifidobacterium spp. isolated from dairy and pharmaceutical products. Int. J. Food Microbiol. 2007, 115, 35-42. [CrossRef]

62. Stefańska, I.; Kwiecień, E.; Jóźwiak-Piasecka, K.; Garbowska, M.; Binek, M.; Rzewuska, M. Antimicrobial susceptibility of lactic acid bacteria strains of potential use as feed additives-The basic safety and usefulness criterion. Front. Vet. Sci. 2021, 9, 687071. [CrossRef] 